\title{
Juvenile Dermatomyositis
}

\author{
Jung Woo Rhim, M.D., Ph.D. \\ Department of Pediatrics, Daejeon St. Mary's Hospital, College of Medicine, The Catholic University of Korea, Seoul, Korea
}

\begin{abstract}
Juvenile dermatomyositis (JDM) is a systemic capillary vasculopathy. Patients present with proximal muscle weakness, raised muscle enzymes, and pathognomic skin rashes such as heliotrope rash, Gottron's papules. Main complications are calcinosis, lipodystrophy, osteoporosis. Complement-mediated damage of vessels is a major mechanism. Magnetic resonance imaging is currently widely used to diagnosis of JDM. The goals of treatment are to control inflammatory myositis and prevent disease complication. Early, aggressive treatment of JDM associated with a better prognosis. High-dose corticosteroids in combination with methotrexate is the mainstay of treatment. The course of JDM is variable. (J Rheum Dis 2022;29:14-21)
\end{abstract}

Key Words. Juvenile dermatomyositis, Muscle weakness, Rash

\section{INTRODUCTION}

Juvenile dermatomyositis (JDM) is the most common idiopathic inflammatory myopathies (IIM) in children. It is a systemic capillary vasculopathy. Patients present with proximal muscle weakness, raised muscle enzymes, and pathognomic skin rashes such as heliotrope rash, Gottron's papules. The course of JDM is variable. Author review some important advances in understading of pathogenesis, epidemiology, clinical manifestations, and treatment of JDM.

\section{MAIN SUBJECTS}

\section{Epidemiology}

JDM occurs in all nations in the world. The peak age at onset is between 4 and 10 years [1]. JDM is more common in girls than boys, with a ratio of 2:1 [2]. The incidence of JDM in the United States 3 per million children per year, which is similar to that in the United Kingdom (3.2 per million children per year) $[3,4]$.

The race distribution of JDM as reported in the US register indicated a predominance of white non-Hispanics
(65.1\%), followed by Hispanics (14.2\%) [3].

\section{Pathogenesis}

The pathogenesis of JDM is not clearly understood. It appears that children with genetic susceptibility to JDM (HLA-DQA1*0501, HLA-DQA*0301, HLA-DRB1*0301) may have exposure to environmental triggers such as infection [5].

Complement-mediated damage of vessels is a major mechanism, with activated complement inducing further cytokine release an vessel injury via the membrane attack complex.

The importance of type 1 interferon in JDM is becoming evident. An inflammatory cascade with type 1 interferon response leads to overexpression of major histocompatibility complex (MHC) class I and maturation of dendritic cells. Overexpression of MHC class I upregulates adhesion molecules, which influence migration of lymphocytes, leading to inflammatory infiltration of muscle [6].

\section{Clinical manifestations}

Symmetrical proximal muscle weakness is the hallmark of JDM. Weakness is often insidious and difficult to differ-

\footnotetext{
Received : August 23, 2021, Revised : December 9, 2021, Accepted : December 9, 2021

Corresponding to : Jung Woo Rhim (iD http://orcid.org/0000-0002-0227-3809

Department of Pediatrics, Daejeon St. Mary's Hospital, College of Medicine, The Catholic University of Korea, 64 Daeheung-ro, Jung-gu, Daejeon 34943, Korea. E-mail : benign7@hanmail.net
}

Copyright (C) 2022 by The Korean College of Rheumatology.

This is an Open Access article, which permits unrestricted non-commerical use, distribution, and reproduction in any medium, provided the original work is properly cited. 
entiate from fatigue at onset. The weakness probably affects all muscle groups but is most obvious in the shoulder girdle, hip flexors, and neck flexors. Patients may have difficulty raising arms, combing hair, climbing stairs, and getting out of bed. Findings on examination include the Gower sign and Trendelenburg sign. Each reflecting proximal lower extremity weakness and gluteal muscle weakness. The affected muscles may be tender, edematous. Weakness of the palatal and pharyngeal muscles manifests clinically by dysphonia, dysphagia, nasal speech, and regurgitation of liquids through the nose. Respiratory muscle weakness can be a medical emergency and lead to respiratory failure.

Arthralgia or arthritis are often seen in early phase of disease course. The arthritis is nonerosive and frequently involves the knees [7].

Pathognomonic rash include heliotrope rash, Gottron's papules, periungual erythema with capillary loop abnormalities. The heliotrope rash is a symmetrical erythematous to violaceous rash of the upper eyelids, often accompanied periorbital edema. Facial erythema crossing the nasolabial folds is common, in contrast to the malar rash of systemic lupus erythematosus. Gottron's papules are an erythematous, shiny, thickened plaques over the dorsal surfaces of the metacarpophalangeal, proximal interphalangeal joints and occasionally on the elbows, knees, ankle malleoli. JDM patients often exhibit photosensitivity to ultraviolet light exposure with erythema in sun-exposed areas. If seen over the posterior neck, upper back, shoulder, this erythema is known as the "shawl sign", and anterior neck, upper chest, this erythema is known as the "V sign".

Evidence of small vessel vasculopathy is often visible in the nailfolds as individual capillary loops that are dilated, tortuous, or dropout. Nailfold capillary abnormalities may be observed in the clinic using a magnifier such as ophthalmoscope. Patients with active disease have a greater degree of nailfold capillary abnormalities compared with those with inactive disease [8]. Severe vasculopathy causes ulcerative skin lesions on fingers, arms, toes.

Calcinosis is reported in up to $30 \%$ of JDM patients [9]. Calcinosis reflects a dystrophic deposition of the calcium phosphate, hydroxyapatite in the skin, soft tissue. Calcific lesions tend to be at pressure points, such as buttocks, knees, and elbows. Calcinosis is thought to be associated with a delayed diagnosis, untreated disease, a chronic course, and inadequate therapy.
Pulmonary involvement in JDM is rare, but serious complication. Pulmonary diseases include interstitial lung disease, aspiration pneumonia secondary to pharyngeal and esophageal dysmotility, and alveolar hypoventilation secondary to respiratory muscle weakness.

Vasculopathy of the gastrointestinal (GI) tract develop in severe JDM, with severe abdominal pain, ulceration, hemorrhage, perforation, and infarction. Clinically important GI involvement is rare, but it is one of the causes of death in JDM.

\section{Diagnosis}

The diagnosis of JDM is made through Bohan and Peter [10] criteria published in 1975. This criteria include the following findings: classic rash (heliotrope rash, Gottron's papule), proximal muscle weakness, elevation of the serum level of one of the muscle enzymes, electromyography (EMG) demonstrating denervation and myopathy, and a muscle biopsy consistent with inflammatory myosistis. According to the 1975 criteria, a diagnosis is considered definite if a patient presents with 3 criteria in addition to the classic rash, or probable if a patient presents with 2 criteria plus the rash (Table 1).

Because of their invasive nature muscle biopsy and EMG are no longer used as frequently. In practice, magnetic resonance imaging (MRI) is currently widely used to diagnosis of JDM, although it is not part of the Bohan and Peter criteria [11].

In 2017, the newly developed European League Against

Table 1. Diagnostic criteria for juvenile dermatomyositis

\begin{tabular}{|c|c|}
\hline Classic rash & $\begin{array}{l}\text { Heliotrope rash of the eyelids } \\
\text { Gottron's papules }\end{array}$ \\
\hline \multicolumn{2}{|l|}{ Plus 3 of the following: } \\
\hline Weakness & $\begin{array}{l}\text { Symmetric } \\
\text { Proximal }\end{array}$ \\
\hline $\begin{array}{l}\text { Muscle enzyme } \\
\text { elevation }(\geq 1)\end{array}$ & $\begin{array}{l}\text { Creatine kinase } \\
\text { Aspartate aminotransferase } \\
\text { Lactate dehydrogenase } \\
\text { Aldolase }\end{array}$ \\
\hline $\begin{array}{l}\text { Electromyographic } \\
\text { changes }\end{array}$ & $\begin{array}{l}\text { Short, small polyphasic motor unit } \\
\text { potentials } \\
\text { Fibrillations } \\
\text { Positive sharp waves } \\
\text { Insertional irritability } \\
\text { Bizarre, high-frequency repetitive } \\
\text { discharges }\end{array}$ \\
\hline Muscle biopsy & $\begin{array}{l}\text { Necrosis } \\
\text { Inflammation }\end{array}$ \\
\hline
\end{tabular}


Table 2. EULAR/ACR classification criteria for adult and juvenile IIMs

\begin{tabular}{|c|c|c|c|}
\hline \multicolumn{4}{|c|}{ When no better explanation for the symptoms and signs exists, these classification criteria can be used } \\
\hline \multirow[b]{2}{*}{ Variable } & \multirow[b]{2}{*}{ Definition } & \multicolumn{2}{|c|}{ Score points } \\
\hline & & $\begin{array}{l}\text { Without muscle } \\
\text { biopsy }\end{array}$ & $\begin{array}{l}\text { With muscle } \\
\text { biopsy }\end{array}$ \\
\hline \multicolumn{4}{|l|}{ Age of onset } \\
\hline $\begin{array}{l}\text { Age of onset of first symptom assumed to be } \\
\text { related to the disease } \geq 18 \text { years and }<40 \text { years }\end{array}$ & $\begin{array}{l}\geq 18 \text { age (years) at onset of first symptom } \\
\text { assumed to be related to the disease }<40\end{array}$ & 1.3 & 1.5 \\
\hline $\begin{array}{l}\text { Age of onset of first symptom assumed to be } \\
\text { related to the disease } \geq 40 \text { years }\end{array}$ & $\begin{array}{l}\text { Age (years) at onset of first symptom } \\
\text { assumed to be related to the disease } \geq 40\end{array}$ & 2.1 & 2.2 \\
\hline \multicolumn{4}{|l|}{ Muscle weakness } \\
\hline $\begin{array}{l}\text { Objective symmetric weakness, usually } \\
\text { progressive, of the proximal upper extremities }\end{array}$ & $\begin{array}{l}\text { Weakness of proximal upper extremities as } \\
\text { defined by manual muscle testing or other } \\
\text { objective strength testing, which is present } \\
\text { on both sides and is usually progressive } \\
\text { over time }\end{array}$ & 0.7 & 0.7 \\
\hline $\begin{array}{l}\text { Objective symmetric weakness, usually } \\
\text { progressive, of the proximal lower extremities }\end{array}$ & $\begin{array}{l}\text { Weakness of proximal lower extremities as } \\
\text { defined bymanual muscle testing or other } \\
\text { objective strength testing, which is present } \\
\text { on both sides and is usually progressive } \\
\text { over time }\end{array}$ & 0.8 & 0.5 \\
\hline $\begin{array}{l}\text { Neck flexors are relatively weaker than neck } \\
\text { extensors }\end{array}$ & $\begin{array}{l}\text { Muscle grades for neck flexors are relatively } \\
\text { lower than neck extensors as defined by } \\
\text { manual muscle testing or other objective } \\
\text { strength testing }\end{array}$ & 1.9 & 1.6 \\
\hline $\begin{array}{l}\text { In the legs, proximal muscles are relatively } \\
\text { weaker than distal muscles }\end{array}$ & $\begin{array}{l}\text { Muscle grades for proximal muscles in the } \\
\text { legs are relatively lower than distal muscles } \\
\text { in the legs as defined by manual muscle } \\
\text { testing or other objective strength testing }\end{array}$ & 0.9 & 1.2 \\
\hline \multicolumn{4}{|l|}{ Skin manifestations } \\
\hline Heliotrope rash & $\begin{array}{l}\text { Purple, lilac-colored, or erythematous } \\
\text { patches over the eyelids or in a periorbital } \\
\text { distribution, often associated with } \\
\text { periorbital edema }\end{array}$ & 3.1 & 3.2 \\
\hline Gottron's papules & $\begin{array}{l}\text { Erythematous to violaceous papules over the } \\
\text { extensor surfaces of joints, which are } \\
\text { sometimes scaly. May occur over the finger } \\
\text { joints, elbows, knees, malleoli, and toes }\end{array}$ & 2.1 & 2.7 \\
\hline Gottron's sign & $\begin{array}{l}\text { Erythematous to violaceous macules over } \\
\text { the extensor surfaces of joints, which are } \\
\text { not palpable }\end{array}$ & 3.3 & 3.7 \\
\hline \multicolumn{4}{|l|}{ Other clinical manifestations } \\
\hline Dysphagia or esophageal dysmotility & $\begin{array}{l}\text { Difficulty in swallowing or objective } \\
\text { evidence of abnormal motility of the } \\
\text { esophagus }\end{array}$ & 0.7 & 0.6 \\
\hline \multicolumn{4}{|l|}{ Laboratory measurements } \\
\hline $\begin{array}{l}\text { Anti-Jo-1 (anti-histidyl-transfer RNA synthetase) } \\
\text { autoantibody present }\end{array}$ & $\begin{array}{l}\text { Autoantibody testing in serum performed } \\
\text { with standardized and validated test, } \\
\text { showing positive result }\end{array}$ & 3.9 & 3.8 \\
\hline
\end{tabular}


Table 2. Continued

\begin{tabular}{|c|c|c|c|}
\hline \multicolumn{4}{|c|}{ When no better explanation for the symptoms and signs exists, these classification criteria can be used } \\
\hline \multirow[b]{2}{*}{ Variable } & \multirow[b]{2}{*}{ Definition } & \multicolumn{2}{|c|}{ Score points } \\
\hline & & $\begin{array}{l}\text { Without muscle } \\
\text { biopsy }\end{array}$ & $\begin{array}{l}\text { With muscle } \\
\text { biopsy }\end{array}$ \\
\hline $\begin{array}{l}\text { Elevated serum levels of } \mathrm{CK}^{*} \text { or } \mathrm{LDH}^{*} \text { or } \mathrm{AST}^{*} \\
\text { or } \mathrm{ALT}^{*}\end{array}$ & $\begin{array}{l}\text { The most abnormal test values during the } \\
\text { disease course (highest absolute level of } \\
\text { enzyme) above the relevant upper limit of } \\
\text { normal }\end{array}$ & 1.3 & 1.4 \\
\hline \multicolumn{4}{|l|}{ Muscle biopsy features-presence of: } \\
\hline $\begin{array}{l}\text { Endomysial infiltration of mononuclear cells } \\
\text { surrounding, but not invading, myofibers }\end{array}$ & $\begin{array}{l}\text { Muscle biopsy reveals endomysial } \\
\text { mononuclear cells abutting the } \\
\text { sarcolemma of otherwise healthy, } \\
\text { non-necrotic muscle fibers, but there is no } \\
\text { clear invasion of the muscle fibers }\end{array}$ & & 1.7 \\
\hline $\begin{array}{l}\text { Perimysial and/or perivascular infiltration of } \\
\text { mononuclear cells }\end{array}$ & $\begin{array}{l}\text { Mononuclear cells are located in the } \\
\text { perimysium and/or located around blood } \\
\text { vessels (in either perimysial or endomysial } \\
\text { vessels) }\end{array}$ & & 1.2 \\
\hline Perifascicular atrophy & $\begin{array}{l}\text { Muscle biopsy reveals several rows of } \\
\text { muscle fibers, which are smaller in the } \\
\text { perifascicular region than fibers more } \\
\text { centrally located }\end{array}$ & & 1.9 \\
\hline Rimmed vacuoles & $\begin{array}{l}\text { Rimmed vacuoles are bluish by hematoxylin } \\
\text { and eosin staining and reddish by modified } \\
\text { Gomori trichrome stain }\end{array}$ & & 3.1 \\
\hline
\end{tabular}

EULAR/ACR: European League Against Rheumatism/American College of Rheumatology, IIMs: idiopathic inflammatory myopathies, CK: creatine kinase, LDH: lactate dehydrogenase, AST: aspartate aminotransferase, ALT: alanine aminotransferase. *Serum levels above the upper limit of normal.

Rheumatism/American College of Rheumatology (EULAR/ ACR) classification criteria were published [12]. This criteria demonstrated high sensitivity and specificity. The criteria provide a score that is calculated from age of onset, variables of muscle weakness, skin manifestations, other clinical manifestations, laboratory measurements, and muscle biopsy findings. Because fewer pediatric patients undergo muscle biopsies, there is an additional scoring algorithm that does not include biopsy variables. Definite IIM corresponds to a probability of $90 \%$ or greater (total score of $\geq 7.5$ without muscle biopsy or $\geq 8.7$ with muscle biopsy). A total score of 5.5 or greater to less than 7.5 without biopsy or 6.7 or more to less than 8.7 with biopsy is classified as probable IIM, with a probability of $55 \%$ or more to less than $90 \%$. A total score of less than 5.3 without biopsy or less than 6.5 with biopsy is classified as possible IIM with a probability of $50 \%$ or more to less than $55 \%$ (Table 2). A patient classified with IIM by the EULAR/ACR classification criteria (probability of IIM $\geq 55 \%$ ) can be further subclassified with a classification tree (Figure 1).

\section{Laboratory findings}

Elevations in a number of muscle-derived enzymes, including creatine kinase, lactate dehydrogenase, aspartate aminotransferase, alanine aminotransferase, aldolase, are seen in JDM. LDH is better at reflecting the global activity and predicting relapse of disease. Erythrocyte sedimentation rate and C-reactive protein, may be elevated or normal. Antinuclear antibody is positive in $>80 \%$ of JDM, and rheumatoid factor is typically negative [13].

Myositis-specific antibodies are exclusively found in children with IIM, and not in other autoimmune conditions such as juvenile idiopathic arthritis, systemic lupus erythematosus.

Patients with antitranscription intermediary factor 1 gamma antibodies tend to have cutaneous ulceration and show typical skin features such as Gottron papules, shawl 


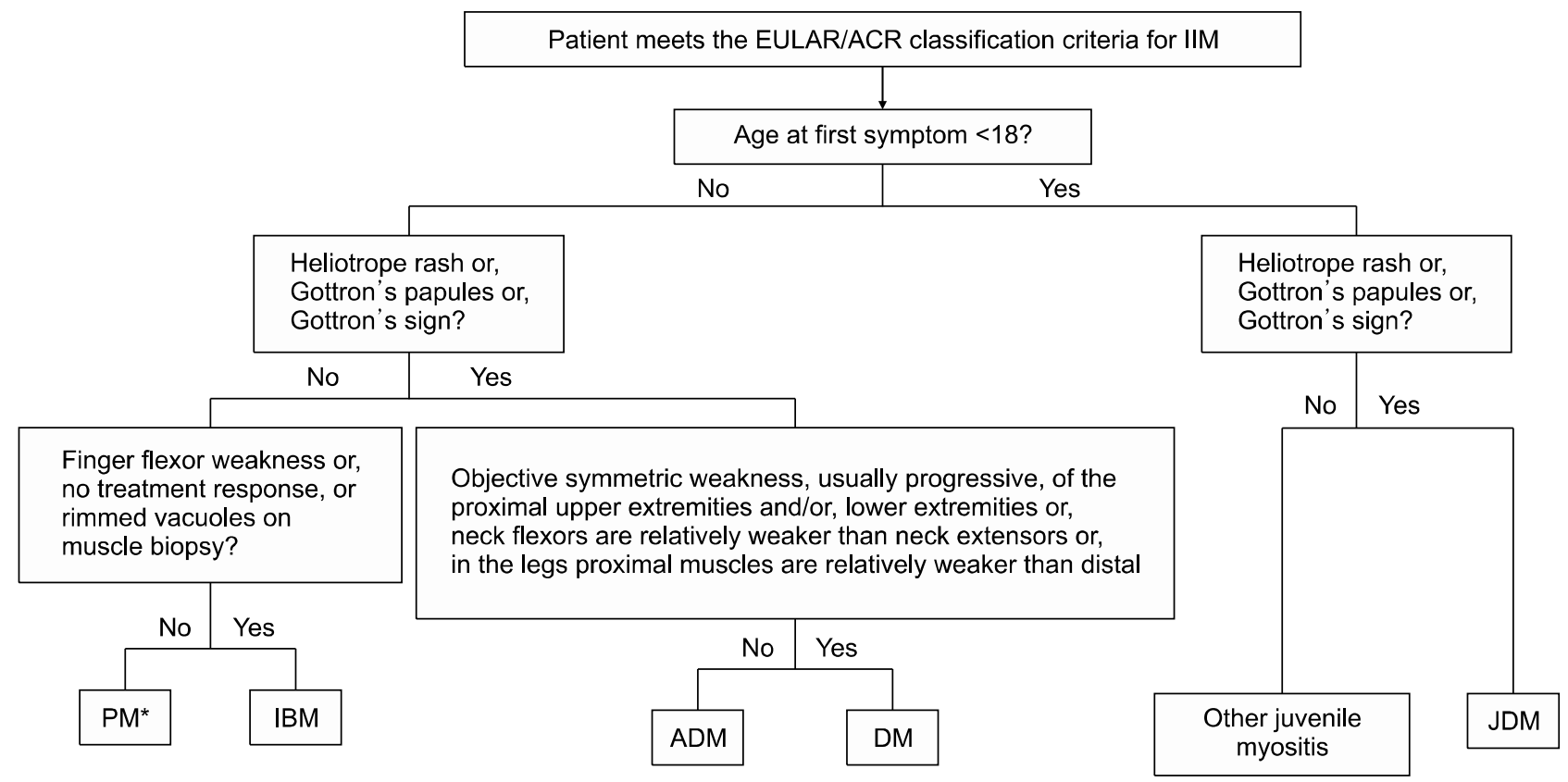

Figure 1. Classification tree for subgroups of idiopathic inflammatory myopathies (IIM). PM: polymyositis, IBM: inclusion body myositis, ADM: amyopathic dermatomyositis, DM: dermatomyositis, JDM: juvenile dermatomyositis, EULAR/ACR: European League Against Rheumatism/American College of Rheumatology. *The PM subset includes immune-mediated necrotizing myopathies (IMNM).

sign, and need more aggressive treatment. Patients with 3-hydroxy-3-methylglutaryl-coenzyme A reductase present with profound weakness and have only a partial response to immunosuppressive medications. Intravenous immunoglobulin (IVIG) seems to be effective for these children. Antinuclear matrix protein 2 antibodies is shown to be associated with younger age at disease onset, muscle cramps, dysphonia, a greater degree of muscle weakness, and calcinosis. Patients with antisignal recognition peptide antibodies have a high frequency of severe muscle weakness and cardiac abnormalities. Anti-Mi-2 antibodies were strongly associated with edema and a greater degree of weakness, malar rash, Gottron papules, and heliotrope rash. Patients with these antibodies usually have high antinulclear abtibody (ANA) titers [14].

MRI aid both diagnosis and monitor disease activity. T1-weighted images of the thigh demonstrate muscle atrophy and fatty infiltration in the presence of chronic disease. T2-weighted images with fat suppression demonstrate soft tissue edema and active inflammation. Short tau inversion recovery images improve visualization of inflammatory change.

\section{Treatment}

The goals of treatment are to control inflammatory my- ositis and prevent disease complication (e.g., calcinosis and contratures). There are no adequate controlled trials in the management of JDM. Thus treatments are based on clinical experience. Early, aggressive treatment of JDM associated with a better prognosis. Corticosteroids in combination with another immunosuppressive medication (most commonly methotrexate) is the mainstay of treatment.

Traditionally, standard treatment for milder cases has been high-dose oral prednisone at $2 \mathrm{mg} / \mathrm{kg} /$ day (maximum dose $60 \mathrm{mg}$ daily), which is continued until clinical and laboratory improvement are evident and then slowly tapered over at least 2-year period [15]. In more severe cases with dysphagia, dysphonia, pulmonary involvement, high-dose intravenous methylprednisolone $(30 \mathrm{mg} / \mathrm{kg} / \mathrm{day}$, maximum dose $1 \mathrm{~g}$ daily) is used. With corticosteroids treatment, however, most patients suffer adverse effects, including cushingoid appearance, cataracts, osteoporosis, and growth retardation. As a result, many JDM patients are now treated with adjunctive immunosuppressant in an attempt to spare corticosteroids.

Oral or subcutaneous methotrexate $\left(15 \mathrm{mg} / \mathrm{m}^{2}\right.$ per week, maximum $40 \mathrm{mg}$ ) is widely used as a corticosteroid-sparing agent in JDM. Patients given methotrexate $\left(15 \mathrm{mg} / \mathrm{m}^{2}\right.$ per week orally or subcutaneously) at dis- 
ease onset had a lower cumulative prednisone dose, less weight gain and improved height velocity, but achieved the same disease control as the comparison group who were treated only with prednisone [16]. Adverse events of methotrexate include immunosuppression, hepatitis, nausea, vomiting, and teratogenicity. Folic acid is typically given with methotrexate starting at a dose of $1 \mathrm{mg}$ daily to reduce side effects of folate inhibition (anemia, oral ulcers).

Hydroxychloroquine is used as a secondary diseasemodifying agent to reduce cutaneous disease and maintain remission. The recommendation dose is $5 \mathrm{mg} / \mathrm{kg}$ per day orally in either tablet or liquid form.

IVIG is now widely used as an adjunctive therapy for corticosteroid-resistant patients, especially resistant skin rash. The recommendation regimen is IVIG at $2 \mathrm{~g} / \mathrm{kg}$ per infusion (maximum $70 \mathrm{~g}$ ), with single infusion administered every 2 weeks for 5 doses, followed by monthly infusions for 2 years.

Cyclosporine is now most often considered in patients who are intolerant to methotrexate. The starting dose of cyclosporine is 3 to $5 \mathrm{mg} / \mathrm{kg}$ per day. Adverse events of cyclosporine are hypertrichosis, hypertension, hirsutism, and abdominal pain [17].

Recently, the efficacy on skin, muscle and global disease activity of cyclophosphamide has been reported in 56 severe and refractory cases of JDM [18]. The cyclophosphamide regimen in this study was $500 \mathrm{mg} / \mathrm{m}^{2}$ (maximum $500 \mathrm{mg}$ ) administered intravenously every 2 weeks for the first 3 doses, followed by $750 \mathrm{mg} / \mathrm{m}^{2}$ (maximum $1.2 \mathrm{~g}$ ) every 3 to 4 weeks (according to the response, for a total of 6 to 7 doses).

A retrospective study of 50 JDM patients who received Mycophenolate Mofetil (MMF) as adjunctive treatment demonstrated a decrease in disease activity of both skin and muscle inflammation at 12-month follow-up [19]. Infection was the most common side effect and patients should be monitored for this complication. MMF is often used for patients who have methotrexate intolerance and persistent skin disease.

Anti-B-cell therapy with rituximab has been suggested as being potentially useful in treating JDM. Rituximab, anti-CD20 monoclonal antibody, has been reported to improve disease activity in a small case series of four JDM patients [20]. Reports of the use of other biological agents such as tumor necrosis factor (TNF)- $\alpha$ inhibitors, abatacept, tofacitinib are based on case reports with mixed results.
Other treatments including systemic tacrolimus, tofacitinib for severe disease have shown some merit in refractory cases.

Physical therapy might improve muscle strength and prevent contracture [21]. Bed rest is not indicated. JDM patients should apply photoprotective agents daily, even in winter and on cloudy days. Calcium and vitamin D are often given to reduce osteoporosis and osteopenia.

There is no standardized treatment of JDM-associated calcinosis. Current knowledge of treatment outcomes is confined to small series and case reports. Treatments were separated into two categories: immunomodulatory and alternative agents, the latter including drugs with non-immunosuppressive actions, such as altering calcium and phosphorus metabolism. Of the immunomodulatory agents, the most frequently used include IVIG, systemic glucocorticoids and methotrexate. Less frequently used agents include TNF- $\alpha$ inhibitors, rituximab, and abatacept. For alternative agents, bisphosphonates were the most frequently used, followed by calcium channel blockers, intravenous/topical thiosulfate, aluminum hydroxide and warfarin. Bisphosphonates inhibit calcium turnover and remodeling [22]. Surgical removal should be considered in cases where the lesions cause significant limitation in mobility or significant pain

\section{Clinical assessment}

Muscle strength should be assessed at diagnosis and serially during follow-up. This is often done using Manual muscle testing of the standardized 8 muscles (MMT8) or Childhood Myositis Assessment Scale (CMAS). MMT8 assess 8 proximal (deltoid, biceps, gluteus maximus, gluteus medius, quadriceps), distal (wrist extensors, ankle dorsiflexors), and axial (neck flexors) muscle groups. MMT8 has been used as a primary end point for JDM clinical trials and in clinics follow patients progress. CMAS is a observational performance-based instrument of 14 functional tasks to assess muscle endurance, muscle function, strength. CMAS may be more informative but takes 15 minutes to perform [23].

\section{Complications}

JDM patients with acute and severe weakness are at risk for aspiration pneumonia and respiratory failure. Crampy abdominal pain and occult GI bleeding may indicate bowel wall vasculitis and lead to ischemia.

Lipodystrophy manifests in 14\% 25\% of patients with JDM. This is characterized by a progressive, and sym- 
metrical loss of subcutaneous fat. Lipodystrophy has been associated with insulin resistance, dyslipidemia, and type 2 diabetes.

\section{Prognosis}

Before the introduction of corticosteroid treatment, prognosis in JDM is very poor, with one third of the patients recovering without complications, one third developing disability, and one third dying. After the introduction of corticosteroid treatment, the mortality rate dropped to $1 \%$.

At 7 years of follow-up, $75 \%$ of patients have little to no residual disability, but $25 \%$ continue to have chronic muscle weakness and $40 \%$ have chronic rash.

\section{CONCLUSION}

JDM is a rare, systemic capillary vasculopathy. It is characterized by symmetrical muscle weakness, pathognomic skin rash, and raised muscle enzymes. JDM requires aggressive anti-inflammatory and immunosuppressive therapy.

\section{CONFLICT OF INTEREST}

No potential conflict of interest relevant to this article was reported.

\section{REFERENCES}

1. Mathiesen PR, Zak M, Herlin T, Nielsen SM. Clinical features and outcome in a Danish cohort of juvenile dermatomyositis patients. Clin Exp Rheumatol 2010;28:782-9.

2. Robinson AB, Hoeltzel MF, Wahezi DM, Becker ML, Kessler EA, Schmeling $\mathrm{H}$, et al. Clinical characteristics of children with juvenile dermatomyositis: the Childhood Arthritis and Rheumatology Research Alliance Registry. Arthritis Care Res (Hoboken) 2014;66:404-10.

3. Mendez EP, Lipton R, Ramsey-Goldman R, Roettcher P, Bowyer S, Dyer A, et al. US incidence of juvenile dermatomyositis, 1995-1998: results from the National Institute of Arthritis and Musculoskeletal and Skin Diseases Registry. Arthritis Rheum 2003;49:300-5.

4. Symmons DP, Sills JA, Davis SM. The incidence of juvenile dermatomyositis: results from a nation-wide study. $\mathrm{Br} \mathrm{J}$ Rheumatol 1995;34:732-6.

5. Mamyrova G, O'Hanlon TP, Monroe JB, Carrick DM, Malley JD, Adams S, et al. Immunogenetic risk and protective factors for juvenile dermatomyositis in Caucasians. Arthritis Rheum 2006;54:3979-87.

6. Khanna S, Reed AM. Immunopathogenesis of juvenile dermatomyositis. Muscle Nerve 2010;41:581-92.

7. Tse S, Lubelsky S, Gordon M, Al Mayouf SM, Babyn PS,
Laxer RM, et al. The arthritis of inflammatory childhood myositis syndromes. J Rheumatol 2001;28:192-7.

8. Barth Z, Witczak BN, Flatø B, Koller A, Sjaastad I, Sanner H. Assessment of microvascular abnormalities by nailfold capillaroscopy in juvenile dermatomyositis after medium- to long-term followup. Arthritis Care Res (Hoboken) 2018;70: 768-76.

9. Huber AM, Lang B, LeBlanc CM, Birdi N, Bolaria RK, Malleson $\mathrm{P}$, et al. Medium- and long-term functional outcomes in a multicenter cohort of children with juvenile dermatomyositis. Arthritis Rheum 2000;43:541-9.

10. Bohan A, Peter JB. Polymyositis and dermatomyositis (first of two parts). N Engl J Med 1975;292:344-7.

11. Brown VE, Pilkington CA, Feldman BM, Davidson JE; Network for Juvenile Dermatomyositis, Paediatric Rheumatology European Society (PReS). An international consensus survey of the diagnostic criteria for juvenile dermatomyositis (JDM). Rheumatology (Oxford) 2006;45:990-3.

12. Lundberg IE, Tjärnlund $A$, Bottai $M$, Werth VP, Pilkington C, de Visser M, et al. 2017 European League Against Rheumatism/American College of Rheumatology classification criteria for adult and juvenile idiopathic inflammatory myopathies and their major subgroups. Arthritis Rheumatol 2017;69:2271-82.

13. Gowdie PJ, Allen RC, Kornberg AJ, Akikusa JD. Clinical features and disease course of patients with juvenile dermatomyositis. Int J Rheum Dis 2013;16:561-7.

14. Rider LG, Shah M, Mamyrova G, Huber AM, Rice MM, Targoff IN, et al. The myositis autoantibody phenotypes of the juvenile idiopathic inflammatory myopathies. Medicine (Baltimore) 2013;92:223-43.

15. Bowyer SL, Blane CE, Sullivan DB, Cassidy JT. Childhood dermatomyositis: factors predicting functional outcome and development of dystrophic calcification. J Pediatr 1983; 103:882-8.

16. Ramanan AV, Campbell-Webster N, Ota S, Parker S, Tran $\mathrm{D}$, Tyrrell PN, et al. The effectiveness of treating juvenile dermatomyositis with methotrexate and aggressively tapered corticosteroids. Arthritis Rheum 2005;52:3570-8.

17. Ruperto N, Pistorio A, Oliveira S, Zulian F, Cuttica R, Ravelli A, et al. Prednisone versus prednisone plus ciclosporin versus prednisone plus methotrexate in new-onset juvenile dermatomyositis: a randomised trial. Lancet 2016; 387:671-8.

18. Deakin CT, Campanilho-Marques R, Simou S, Moraitis E, Wedderburn LR, Pullenayegum E, et al. Efficacy and safety of cyclophosphamide treatment in severe juvenile dermatomyositis shown by marginal structural modeling. Arthritis Rheumatol 2018;70:785-93.

19. Rouster-Stevens KA, Morgan GA, Wang D, Pachman LM. Mycophenolate mofetil: a possible therapeutic agent for children with juvenile dermatomyositis. Arthritis Care Res (Hoboken) 2010;62:1446-51.

20. Cooper MA, Willingham DL, Brown DE, French AR, Shih FF, White AJ. Rituximab for the treatment of juvenile dermatomyositis: a report of four pediatric patients. Arthritis Rheum 2007;56:3107-11.

21. Maillard SM, Jones R, Owens CM, Pilkington C, Woo PM, Wedderburn LR, et al. Quantitative assessments of the effects of a single exercise session on muscles in juvenile dermatomyositis. Arthritis Rheum 2005;53:558-64. 
22. Orandi AB, Baszis KW, Dharnidharka VR, Huber AM, Hoeltzel MF; CARRA Juvenile Myositis subgroup. Assessment, classification and treatment of calcinosis as a complication of juvenile dermatomyositis: a survey of pediatric rheumatologists by the childhood arthritis and rheumatology research alliance (CARRA). Pediatr Rheumatol Online J 2017;
15:71.

23. Huber AM, Feldman BM, Rennebohm RM, Hicks JE, Lindsley $\mathrm{CB}$, Perez MD, et al. Validation and clinical significance of the Childhood Myositis Assessment Scale for assessment of muscle function in the juvenile idiopathic inflammatory myopathies. Arthritis Rheum 2004;50:1595-603. 